University of Nebraska - Lincoln

DigitalCommons@University of Nebraska - Lincoln

\title{
Transition of Cellulose Crystalline Structure and Surface Morphology of Biomass as a Function of Ionic Liquid Pretreatment and Its Relation to Enzymatic Hydrolysis
}

\author{
Gang Cheng \\ Joint BioEnergy Institute \\ Patanjali Varanasi \\ Joint BioEnergy Institute, PVaranasi@lbl.gov \\ Chenlin Li \\ Joint BioEnergy Institute \\ Hanbin Liu \\ Joint BioEnergy Institute \\ Yuri B. Melnichenko \\ Oak Ridge National Laboratory, melnichenkoy@ornl.gov \\ See next page for additional authors \\ Follow this and additional works at: https://digitalcommons.unl.edu/usdoepub \\ Part of the Bioresource and Agricultural Engineering Commons
}

Cheng, Gang; Varanasi, Patanjali; Li, Chenlin; Liu, Hanbin; Melnichenko, Yuri B.; Simmons, Blake A.; Kent, Michael S.; and Singh, Seema, "Transition of Cellulose Crystalline Structure and Surface Morphology of Biomass as a Function of Ionic Liquid Pretreatment and Its Relation to Enzymatic Hydrolysis" (2011). US Department of Energy Publications. 317.

https://digitalcommons.unl.edu/usdoepub/317

This Article is brought to you for free and open access by the U.S. Department of Energy at DigitalCommons@University of Nebraska - Lincoln. It has been accepted for inclusion in US Department of Energy Publications by an authorized administrator of DigitalCommons@University of Nebraska - Lincoln. 


\section{Authors}

Gang Cheng, Patanjali Varanasi, Chenlin Li, Hanbin Liu, Yuri B. Melnichenko, Blake A. Simmons, Michael S. Kent, and Seema Singh 


\title{
Transition of Cellulose Crystalline Structure and Surface Morphology of Biomass as a Function of Ionic Liquid Pretreatment and Its Relation to Enzymatic Hydrolysis
}

\author{
Gang Cheng, ${ }^{+, \neq}$Patanjali Varanasi, ${ }^{+, \neq}$Chenlin Li, ${ }^{+, \neq}$Hanbin Liu, ${ }^{+, \neq}$Yuri B. Melnichenko, \\ Blake A. Simmons, ${ }^{+, \neq}$Michael S. Kent, ${ }^{+, \neq}$and Seema Singh ${ }^{*,+, \neq}$ \\ ${ }^{\dagger}$ Joint BioEnergy Institute, Emeryville, California \\ ${ }^{\mp}$ Sandia National Laboratories, Livermore, California and Albuquerque, New Mexico \\ ${ }^{\S}$ Neutron Scattering Sciences Division, Oak Ridge National Laboratory, Oak Ridge, Tennessee \\ Supporting Information
}

\begin{abstract}
Cellulose is inherently resistant to breakdown, and the native crystalline structure (cellulose I) of cellulose is considered to be one of the major factors limiting its potential in terms of cost-competitive lignocellulosic biofuel production. Here we report the impact of ionic liquid pretreatment on the cellulose crystalline structure in different feedstocks, including microcrystalline cellulose (Avicel), switchgrass (Panicum virgatum), pine (Pinus radiata), and eucalyptus (Eucalyptus

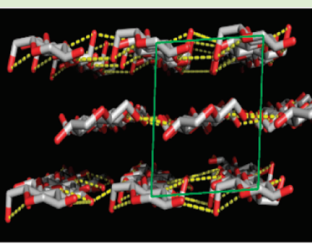

Cellulose $I_{\beta}$

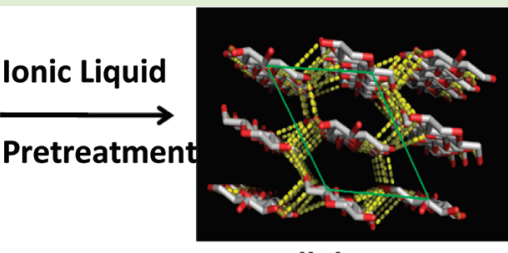

Cellulose II globulus), and its influence on cellulose hydrolysis kinetics of the resultant biomass. These feedstocks were pretreated using 1-ethyl-3-methyl imidazolium acetate $([\mathrm{C} 2 \mathrm{mim}][\mathrm{OAc}])$ at 120 and $160^{\circ} \mathrm{C}$ for $1,3,6$, and $12 \mathrm{~h}$. The influence of the pretreatment conditions on the cellulose crystalline structure was analyzed by X-ray diffraction (XRD). On a larger length scale, the impact of ionic liquid pretreatment on the surface roughness of the biomass was determined by small-angle neutron scattering (SANS). Pretreatment resulted in a loss of native cellulose crystalline structure. However, the transformation processes were distinctly different for Avicel and for the biomass samples. For Avicel, a transformation to cellulose II occurred for all processing conditions. For the biomass samples, the data suggest that pretreatment for most conditions resulted in an expanded cellulose I lattice. For switchgrass, first evidence of cellulose II only occurred after $12 \mathrm{~h}$ of pretreatment at $120^{\circ} \mathrm{C}$. For eucalyptus, first evidence of cellulose II required more intense pretreatment $\left(3 \mathrm{~h}\right.$ at $\left.160^{\circ} \mathrm{C}\right)$. For pine, no clear evidence of cellulose II content was detected for the most intense pretreatment conditions of this study $\left(12 \mathrm{~h}\right.$ at $\left.160{ }^{\circ} \mathrm{C}\right)$. Interestingly, the rate of enzymatic hydrolysis of Avicel was slightly lower for pretreatment at $160{ }^{\circ} \mathrm{C}$ compared with pretreatment at $120^{\circ} \mathrm{C}$. For the biomass samples, the hydrolysis rate was much greater for pretreatment at $160^{\circ} \mathrm{C}$ compared with pretreatment at $120^{\circ} \mathrm{C}$. The result for Avicel can be explained by more complete conversion to cellulose II upon precipitation after pretreatment at $160^{\circ} \mathrm{C}$. By comparison, the result for the biomass samples suggests that another factor, likely lignincarbohydrate complexes, also impacts the rate of cellulose hydrolysis in addition to cellulose crystallinity.
\end{abstract}

\section{INTRODUCTION}

The rapid consumption of fossil fuel resources has motivated research for use of renewable resources to produce chemicals and transportation fuels. ${ }^{1,2}$ Lignocellulosic biomass is of particular interest as a renewable and sustainable means of providing monomeric sugars for fermentation into fuels and chemicals. ${ }^{3-5}$ Lignocellulosic biomass primarily consists of a complex mixture of lignin, hemicellulose, and semicrystalline cellulose, which is naturally resistant to breakdown by pests, disease, and weather. This inherent recalcitrance makes the production of fermentable sugars from lignocellulosic biomass expensive and inefficient as compared with the production of monomeric sugars from starchbased (e.g., corn kernels) feedstocks. Pretreating lignocellulosic biomass to disrupt the lignin - carbohydrate complex, to decrease native cellulose crystallinity (cellulose I), and to partially remove lignin and hemicellulose, has been shown to significantly enhance the subsequent hydrolysis of cellulose. ${ }^{3-5}$ Ionic liquids (ILs) have recently emerged as promising new solvents capable of disrupting the native cellulose crystalline structure, possibly also breaking structurally important chemical linkages, in a wide range of biomass feedstocks. ${ }^{6-9}$ In this process, biomass samples are exposed to ILs at elevated temperatures for a short period of time. An antisolvent is subsequently added to the solution, and the treated biomass samples are recovered as the precipitate.

Pretreatment involves many physicochemical, structural, and compositional changes, and the correlation of each change with the impact on downstream saccharification is essential for optimizing the biomass-to-biofuel conversion process. $8,10,11$ The crystallinity of cellulose is considered to be one of the major

Received: October 17, 2010

Revised: January 27, 2011 
substrate properties that could influence saccharification kinetics and yields. ${ }^{10}{ }^{12}$ Pretreatment of biomass by ILs typically results in a decrease in cellulose crystallinity as well as a transformation of cellulose I to cellulose II, depending on the pretreatment conditions used. ${ }^{6-9}$ Despite an increasing number of publications on the pretreatment of biomass using ILs over the past few years, there have been few systematic studies of the influence of the pretreatment conditions on the crystalline structure of cellulose present after recovery. In one prior study, 1-n-butyl-3methylimidazolium chloride $([\mathrm{C} 4 \mathrm{mim}] \mathrm{Cl})$ was used to pretreat microcrystalline Avicel at temperatures from 130 to $150{ }^{\circ} \mathrm{C}$ for 10 to $180 \mathrm{~min} .{ }^{13}$ Water, methanol, and ethanol were used as antisolvents for precipitating cellulose from $[\mathrm{C} 4 \mathrm{mim}] \mathrm{Cl}$. XRD analysis of the regenerated Avicel revealed amorphous structures, independent of the pretreatment time and the antisolvents used. ${ }^{13}$ Another recent investigation reported significant crystallinity in regenerated Avicel after treatment in $[\mathrm{C} 4 \mathrm{mim}] \mathrm{Cl}$ at $130^{\circ} \mathrm{C}$ for $2 \mathrm{~h}$ and concluded a coexistence of cellulose I and II crystal structures. ${ }^{14}$ These conflicting results underscore the need for systematic studies to be carried out to establish the extent and type of crystallinity present in regenerated cellulose and to correlate these structures with hydrolysis rates. Furthermore, it is important to compare results for a model cellulose substrate with results for biomass samples.

In this work, we used 1-ethyl-3-methyl imidazolium acetate $([\mathrm{C} 2 \mathrm{mim}][\mathrm{OAc}])$ to pretreat Avicel, switchgrass (Panicum virgatum), eucalyptus (Eucalyptus globulus), and pine (Pinus radiata) at 120 and $160{ }^{\circ} \mathrm{C}$ for different periods of time. The changes in the cellulose crystalline structures were tracked by XRD, whereas the impact of the IL pretreatment on the biomass surface morphology was monitored by small-angle neutron scattering (SANS). These results were compared with measured rates of enzymatic hydrolysis to determine the impact of biomass pretreatment on observed enzyme kinetics and yields.

\section{MATERIALS AND METHODS}

Materials. Cellulase (NS50013) and $\beta$-glucosidase (NS50010) were provided by Novozymes (Davis, CA). The IL 1-ethyl-3-methyl imidazolium acetate $([\mathrm{C} 2 \mathrm{mim}][\mathrm{OAc}])(90 \%)$ and Avicel were purchased from Sigma-Aldrich (St. Louis, MO). Eucalyptus and pine were from ArborGen (Sumerville, SC). Switchgrass was received as a gift from Dr. Ken Vogel (USDA, Nebraska).

Cellulose Content. Cellulose content in three types of biomass before and after pretreatment was determined according to the analytical procedure of the National Renewable Energy Laboratory (NREL) by two-step acid hydrolysis. ${ }^{15,16}$ Glucose was analyzed by HPAEC on an ICS-3000 system equipped with an electrochemical detector and a $4 \times$ $250 \mathrm{~mm}$ CarboPac PA20 analytical column (Dionex). ${ }^{8,17}$ Elution was initiated with $97.2 \%(\mathrm{v} / \mathrm{v})$ water and $2.8 \%(\mathrm{v} / \mathrm{v}) 1 \mathrm{M} \mathrm{NaOH}$ for first 15 min with injection volume of $20 \mu \mathrm{L}$. The elution fluid was then switched to $55.0 \%(\mathrm{v} / \mathrm{v})$ water and $45.0 \%(\mathrm{v} / \mathrm{v}) 1 \mathrm{M} \mathrm{NaOH}$ for the next $20 \mathrm{~min}$ and returned to $97.2 \%(\mathrm{v} / \mathrm{v})$ water and $2.8 \%(\mathrm{v} / \mathrm{v}) 1 \mathrm{M} \mathrm{NaOH}$ for the last $10 \mathrm{~min}$ to equilibrate the column. The flow rate was $0.5 \mathrm{~mL} / \mathrm{min}$.

IL Pretreatment. The biomass samples before pretreatment were milled to 40 mesh. Milled biomass (300 mg) was mixed with $9.7 \mathrm{~mL}$ of $\mathrm{IL}$ at room temperature. For Avicel, $180 \mathrm{mg}$ was added to $9.82 \mathrm{~mL}$ of IL. The samples were heated to 120 and $160{ }^{\circ} \mathrm{C}$ without stirring in a Precision Thelco oven for 1, 3, 6, and $12 \mathrm{~h}$.

After the pretreatment was completed, the samples were transferred to $45 \mathrm{~mL}$ of centrifuge tubes. Then, $35 \mathrm{~mL}$ of hot water was added to precipitate the dissolved biomass. The mixture of IL, water, and biomass was centrifuged (Eppendorf centrifuge 5810R) at $11000 \mathrm{rpm}$ to separate the solid (biomass) from the liquid (IL and water). The biomass was further washed with water at least four times to remove the IL. The solid was then lyophilized for 2 days. The pretreatment processing was performed in triplicate.

Enzymatic Saccharification. Batch enzymatic saccharification of pretreated and untreated Avicel, switchgrass, pine, and eucalyptus samples was carried out at $50{ }^{\circ} \mathrm{C}$ in a $50 \mathrm{rpm}$ rotating incubator. All samples were diluted to $5 \mathrm{~g} / \mathrm{L}$ in a $50 \mathrm{mM}$ sodium acetate buffer with $\mathrm{pH}$ 4.8 supplemented with $0.08 \mathrm{~g} / \mathrm{L}$ tetracycline solution for enzymatic hydrolysis. The total batch volume was $5 \mathrm{~mL}$ with cellulase (NS50013) concentration of $50 \mathrm{mg}$ protein/g glucan (3.5 filter paper unit/g glucan) and $\beta$-glucosidase (NS50010) concentration of $5 \mathrm{mg}$ protein $/ \mathrm{g}$ glucan(1.25 Cellobiase unit/g glucan). ${ }^{8}$

The reaction was monitored by taking $50 \mu \mathrm{L}$ of supernatant at specific time intervals, followed by centrifugation at $10000 \mathrm{~g}$ for $5 \mathrm{~min}$, and measuring the release of reducing sugars (mainly glucose plus a small amount of xylose) by DNS assay using D-glucose as a standard. Untreated Avicel controls were run concurrently with all recovered samples to eliminate potential differences in temperature history or enzyme loading. ${ }^{13}$ The initial rates of total soluble reducing sugar formation were calculated based on the sugar released in the first 60 min of hydrolysis. ${ }^{13}$ All assays were performed in triplicate. Error bars show the standard deviation of triplicate measurements.

X-ray Diffraction (XRD). Pretreated and untreated samples of Avicel and the three types of biomass were analyzed by XRD. Following pretreatment, the samples were lyophilized for 2 days after precipitation from the IL solution, and then stored at room temperature prior to XRD analysis. Samples from three pretreatment trials were mixed together for XRD analysis. The samples were scanned on a Siemens D500 $\theta-\theta$ diffractometer equipped with a sealed tube $\mathrm{Cu} \mathrm{K \alpha}$ source, diffracted-beam graphite monochromator, and scintillation detector. Scans were collected from $2 \theta=4$ to $60^{\circ}$ with step size of $0.03^{\circ}$ at $4 \mathrm{~s}$ per step. The following empirical equation was adopted to estimate the amount of cellulose I crystallinity in the untreated biomass samples: ${ }^{18}$

$$
\mathrm{Crl}=\frac{I_{\mathrm{total}}-I_{\mathrm{am}}}{I_{\mathrm{total}}} \times 100
$$

in which $I_{\text {total }}$ is the scattered intensity at the main peak for cellulose I, which usually lies around $22.5^{\circ}$; whereas $I_{\mathrm{am}}$ is the scattered intensity due to the amorphous portion evaluated as the minimum intensity between the main and secondary (the broad peak at $16^{\circ}$ ) peaks. ${ }^{18}$ For cellulose II, the main peak appears as a doublet at 20.0 and $21.9^{\circ}$, and the secondary peak appears at $12 \cdot 1^{\circ} .^{23,24,30}$ The scattered intensity is in arbitrary units and not normalized to sample mass, so ratios of peak heights, rather than absolute intensities, are used for the comparison between different samples. The peak's full width at half-maximum (fwhm), which is a reflection of the size of the crystals, is obtained by fitting the peaks with the Lorentz function. Dislocations/misalignment in the lattices as well as instrument resolution can also contribute to peak broadening.

Small-Angle Neutron Scattering (SANS). SANS experiments were conducted at Oak Ridge National Laboratory (ORNL) on the CG2 (GP-SANS) instrument (http://neutrons.ornl.gov/hfir_instrument_systems/CG-2.shtml) with a neutron wavelength of $\lambda=4.8 \AA(\Delta \lambda / \bar{\lambda}$ $\approx 0.14$ ). Powder samples were sandwiched into $1 \mathrm{~mm}$ homemade quartz cells. Two sample-detector distances were used ( 4.0 and $18.5 \mathrm{~m}$ with a $40 \mathrm{~cm}$ detector offset), which resulted in a $q(=4 \pi \sin \theta / \lambda)$ range of $0.003<q<0.3 \AA^{-1}$. The data were corrected for instrumental background and detector efficiency. Because of uncertainty in the packing density of the powder in the cells, the absolute scattering intensities are reported without normalization to sample mass or volume. 

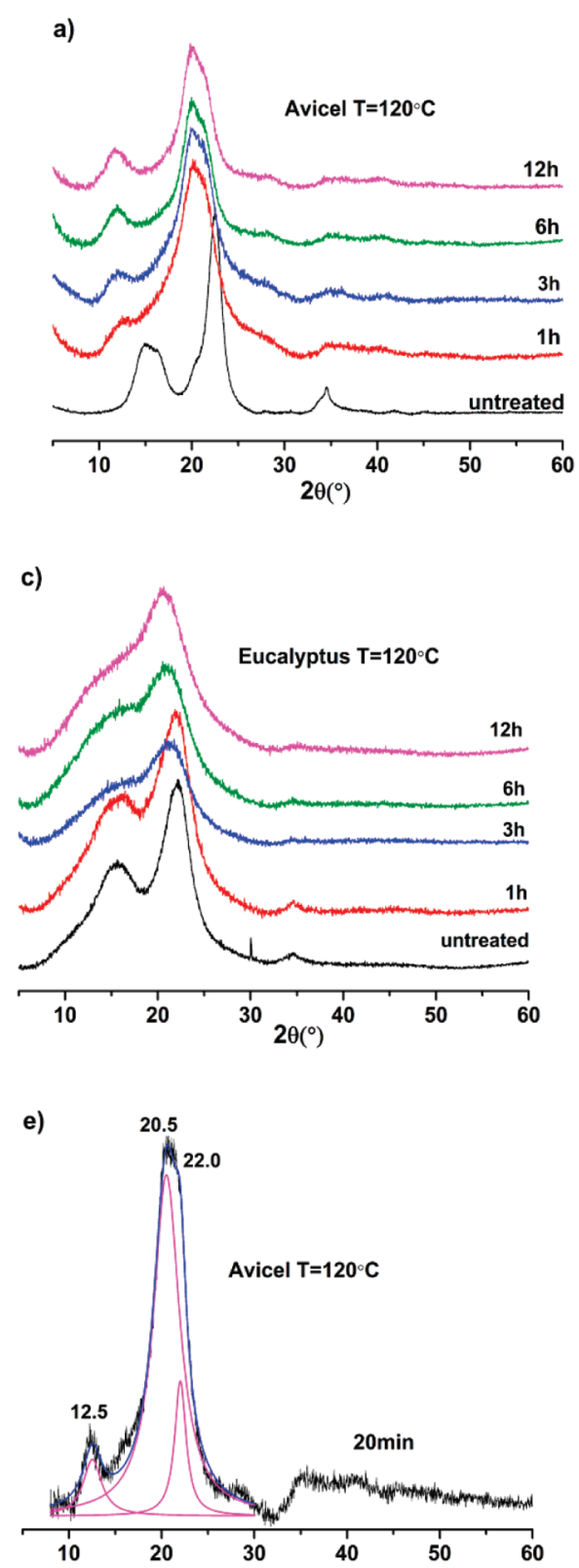
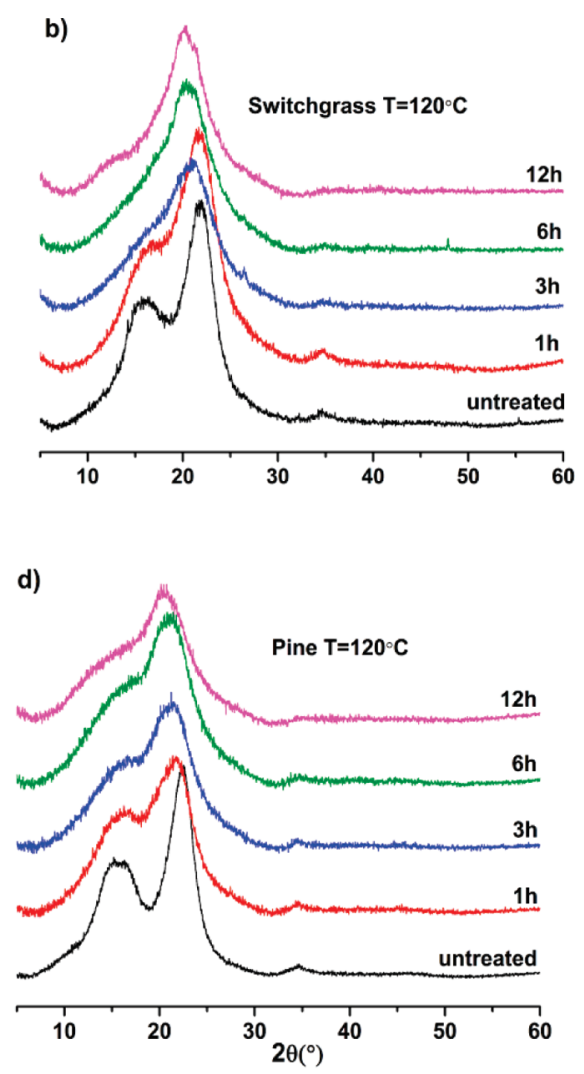

Figure 1. XRD patterns of (a) Avicel, (b) switchgrass, (c) eucalyptus, and (d) pine samples pretreated in [C2mim] $[\mathrm{OAc}]$ at $120^{\circ} \mathrm{C}$ for $1,3,6$, and $12 \mathrm{~h}$. (e) Avicel at $120^{\circ} \mathrm{C}$ for $20 \mathrm{~min}$.

\section{RESULTS}

Changes of Cellulose Crystalline Structure Measured by XRD. In the native state, cellulose exists as a semicrystalline polymer. $^{20}$ In the crystalline regions, the cellulose chains form two distinct allomorphs of cellulose $\mathrm{I}, \mathrm{I}_{\alpha}$ with a triclinic unit cell and $\mathrm{I}_{\beta}$ with a monoclinic unit cell, whose fractional distributions vary among samples of different origin. ${ }^{21}$ In cellulose $\mathrm{I}_{\alpha}$ and $\mathrm{I}_{\beta}$, parallel chains align side-by-side via hydrogen bonding in flat sheets. ${ }^{22}$ Cellulose II is most often obtained from cellulose I via either of two processes: ${ }^{20}$ regeneration and mercerization. In addition, treating cellulose in subcritical water ${ }^{23}$ and ball-milling cellulose in the presence of water ${ }^{24}$ have also been shown to transform cellulose I to cellulose II. In the cellulose II form, chains with opposite polarity are stacked to form corrugated sheets. ${ }^{25}$ Hydrogen bonding exists within the sheets as well as between them.
Figure 1 shows the diffraction patterns of untreated Avicel, switchgrass, eucalyptus, and pine substrates. Three peaks are observed in the diffraction patterns. The main peak position varies with species: $22.5^{\circ}$ for Avicel, $21.8^{\circ}$ for switchgrass, $22.1^{\circ}$ for eucalyptus, and $22.3^{\circ}$ for Pine samples. This peak is indicative of the distance between hydrogen-bonded sheets in cellulose I. There is a broad peak at $\sim 16^{\circ}$, which is known to be a composite of two peaks from $\mathrm{I}_{\beta}\left(16.7\right.$ and $14.9^{\circ}$ from ref 26$), I_{\alpha}$ (16.8 and $14.3^{\circ}$ from ref 26 ), or both. The third small peak at $34.5^{\circ}$ corresponds to $1 / 4$ of the length of one cellobiose unit and arises from ordering along the fiber direction. It is sensitive to the alignment of the chains into fibrils. Both the crystallite size and the moisture content in the samples can affect the observed diffraction peaks. ${ }^{27,28}$

The fraction of crystalline material in the sample is referred to as the crystallinity index $(\mathrm{CrI})$. The concept of $\mathrm{CrI}$ is based on the 

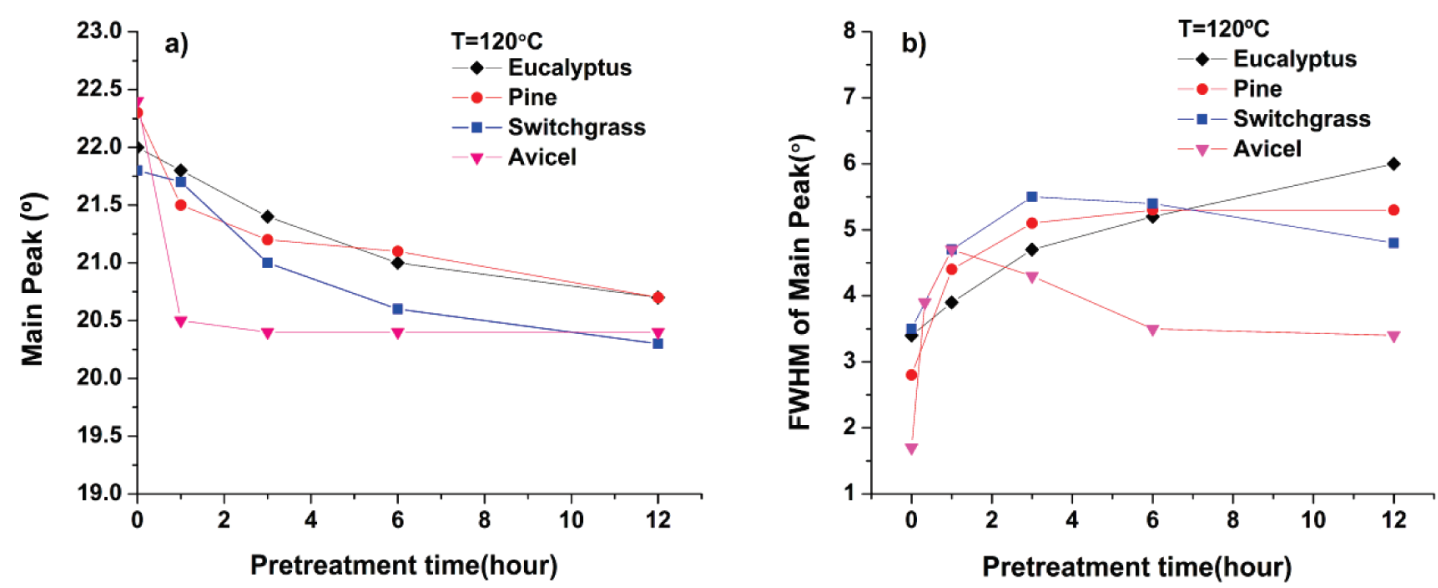

Figure 2. (a) Main peak of the XRD patterns of Avicel and biomass sample pretreated in [C2mim] OAc at $120^{\circ} \mathrm{C}$ for $1,3,6$, and $12 \mathrm{~h}$. (b) FWHM of main peak of the XRD patterns of Avicel and biomass sample pretreated in [C2mim] [OAc] at $120^{\circ} \mathrm{C}$ for $1,3,6$, and $12 \mathrm{~h}$.

assumption that there is only a single crystalline phase along with an amorphous phase. ${ }^{29}$ XRD has long been used to determine the $\mathrm{CrI}$ by assessing the relative contributions of each phase to the overall wide-angle scattering pattern. In addition to XRD, solidstate $\mathrm{C}^{13}$ NMR, FT-IR, and Raman have also been used to estimate the CrI. ${ }^{18,19,31,32,33}$ There are at least four different ways of estimating the CrI based on an XRD pattern, as summarized in a recent review. ${ }^{18}$ The simplest method is based on the ratio of the main peak intensity and the intensity at the minimum between the main peak and the secondary peak (eq 1). This method has been used to compare the relative change in CrI of biomass substrates subjected to different pretreatment conditions. ${ }^{8,11}$ The second approach is based on separation of the peak area into contributions from the amorphous and crystalline portions. Selection of an amorphous standard that accurately represents the amorphous portion in biomass samples is a challenge. The CrI is obtained as the ratio of the area arising from the crystalline phase to the total area. The other two approaches are based on Rietveld refinement and the Debye formula, which require knowledge of the crystal structure and the atomic positions for a uniform crystal. These are less popular because of the fact that they are more difficult to implement and also because of complexities that arise from the fact that samples typically consist of two different crystalline phases: $\mathrm{I}_{\alpha}$ and $\mathrm{I}_{\beta}$.

The CrI cellulose I of untreated Avicel, switchgrass, eucalyptus, and pine, based on the peak height method, is calculated to be $0.82,0.41,0.48$, and 0.57 , respectively. These values are in good agreement with values reported previously by this method: 0.62 to 0.88 for Avicel, ${ }^{12} \sim 0.52$ for switchgrass, ${ }^{35,36}$ and $\sim 0.50$ for eucalyptus. ${ }^{37}$ However, a CrI of 0.21 for switchgrass by the same method has also been reported. ${ }^{9}$ For comparison, a diffraction pattern of Kraft lignin was also taken in this study and was used to represent the amorphous scattering in the calculation of the $\mathrm{CrI}$ via the peak area method. This method gave lower values for the biomass samples: 0.28 for switchgrass, 0.29 for eucalyptus, and 0.47 for pine. A value of $\sim 0.25$ was previously reported for pine based on this method. ${ }^{34}$ The cellulose I CrI of switchgrass, eucalyptus, and pine, normalized to their respective cellulose contents $(39.5 \pm 1.8,41.7 \pm 0.8$, and $38.2 \pm 1.1 \%)$, are 0.70 , 0.70 , and 1.23 . The unphysical value greater than unity indicates error in either cellulose content or in the absolute CrI. Generally speaking, the fact that various ways of estimating CrI are used reflects the complexity of this issue, and new methods are still being developed. ${ }^{33}$ A literature survey showed 70 to $85 \%$ usage of the peak height method in estimating the CrI of commercial celluloses. ${ }^{19}$

The XRD patterns of regenerated Avicel, switchgrass, eucalyptus, and pine after $\mathrm{IL}$ pretreatment at $120^{\circ} \mathrm{C}$ in [C2mim] [OAc] for 1, 3, 6 , and $12 \mathrm{~h}$ are plotted in Figure $1 \mathrm{a}-\mathrm{d}$, respectively. For Avicel, after $\mathrm{IL}$ pretreatment for $1 \mathrm{~h}$, the main peak at $22.5^{\circ}$ disappeared, and a broad asymmetric peak consisting of a doublet at 20.0 and $21.7^{\circ}$ appeared; both the broad peak at $16^{\circ}$ and the small peak at $34.5^{\circ}$ disappeared, and a new peak emerged at $\sim 12.1^{\circ}$. These changes indicate a transformation from cellulose I to cellulose II. ${ }^{23,30}$ Somewhat different effects were observed for the biomass samples. For those samples, the main peak shifts gradually to lower $2 \theta$, and the peak at $12 \cdot 1^{\circ}$ is absent (except for switchgrass treated for $12 \mathrm{~h}$ ). These results suggest an expansion of the cellulose I lattice rather than a transformation to cellulose II, as observed for Avicel. To determine if a gradual shift of the main peak occurs for Avicel at lower pretreatment times, we collected an XRD scan for a sample pretreated for $20 \mathrm{~min}$ (Figure 1e). In that case, the same peaks are present as for the samples treated for longer times.

The positions of the main peak for pretreated Avicel and for the biomass samples as a function of pretreatment time are presented in Figure 2a. In contrast with the rapid shift of the main peak for Avicel, for switchgrass, the main peak shifted to $20.1^{\circ}$ only after a period of between 6 and $12 \mathrm{~h}$. For eucalyptus and pine, after $12 \mathrm{~h}$ of pretreatment the main peaks were at $20.7^{\circ}$. Close inspection of the spectra at lower values of $2 \theta$ further indicates a slower transformation of the crystalline structure for pine and eucalyptus than for switchgrass. For switchgrass, the broad peak at $15.6^{\circ}$ becomes vanishingly small between 3 and 6 $\mathrm{h}$, and a small shoulder at $\sim 12^{\circ}$ appears after $12 \mathrm{~h}$, indicating that a small amount of cellulose II is present. For eucalyptus and pine, the broad peak at $\sim 16^{\circ}$ becomes a shoulder on the main peak with increasing pretreatment time. In addition to the shift of the peak positions, the peak widths also change, suggesting changes in crystallite size, misalignment of crystals, or both. As shown in Figure $2 b$, the FWHM of the main peak increases with pretreatment time for eucalyptus and pine, whereas it drops after $6 \mathrm{~h}$ for switchgrass, which coincides with the generation of cellulose II in switchgrass. In contrast, for Avicel, the FWHM of the cellulose II doublet decreases with pretreatment time after $1 \mathrm{~h}$, indicating increased ordering of the cellulose II lattice or an increase in the size of cellulose II crystallites. 

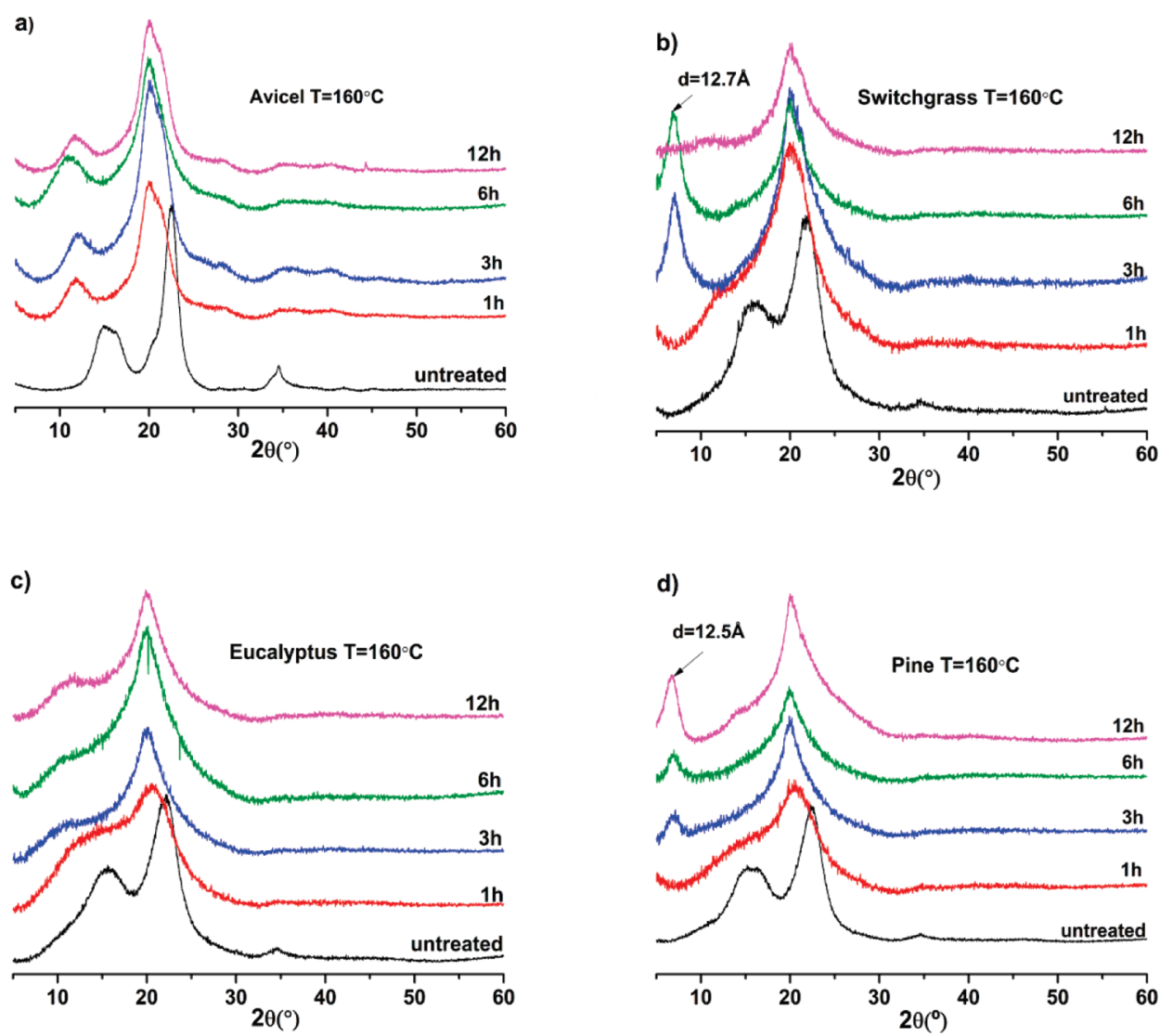

Figure 3. XRD patterns of (a) Avicel, (b) switchgrass, (c) eucalyptus, and (d) pine samples pretreated in [C2mim] $[\mathrm{OAc}]$ at $160{ }^{\circ} \mathrm{C}$ for $1,3,6$, and $12 \mathrm{~h}$.

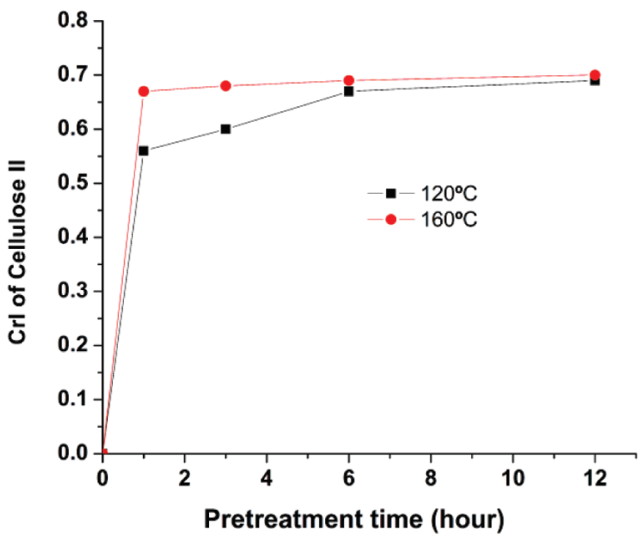

Figure 4. CrI of Cellulose II in Avicel pretreated in [C2mim] [OAc] at 120 and $160^{\circ} \mathrm{C}$ for $1,3,6$, and $12 \mathrm{~h}$.

Figure 3 shows the diffraction patterns of Avicel and the biomass samples treated at $160{ }^{\circ} \mathrm{C}$ for $1,3,6$, and $12 \mathrm{~h}$. The development of the diffraction pattern of Avicel (Figure 3a) with pretreatment time at $160{ }^{\circ} \mathrm{C}$ is qualitatively similar to that at $120^{\circ} \mathrm{C}$. For both pretreatment temperatures the $\mathrm{CrI}$ of cellulose II based on the ratio of the peak heights ${ }^{31}$ at 19.9 and $16.0^{\circ}$ for the Avicel samples is plotted in Figure 4 as a function of pretreatment time. The fraction of cellulose chains transformed into cellulose II after pretreatment for 1 and $3 \mathrm{~h}$ is greater at $160{ }^{\circ} \mathrm{C}$ as compared with $120^{\circ} \mathrm{C}$. After $6 \mathrm{~h}$, the content of cellulose II in the regenerated Avicel is similar for both temperatures. At both pretreatment temperatures, it is evident from the XRD scans that cellulose I is completely absent by $1 \mathrm{~h}$, and so one might expect the same rate of cellulose II formation upon precipitation. However, depolymerization of cellulose chains may occur during dissolution in ILs at high temperatures. ${ }^{38}$ We hypothesize that cellulose chains with lower molecular weights are more readily recrystallized upon precipitation with water than those of higher molecular weight and that this phenomenon could explain the observed differences in the amounts of cellulose II present for the different pretreatment temperatures.

The regenerated switchgrass and eucalyptus samples pretreated in IL at $160{ }^{\circ} \mathrm{C}$ also show clear evidence of cellulose II, indicated in each case by the appearance of a peak around $12.1^{\circ}$. However, no peak is evident around $12.1^{\circ}$ for pine, suggesting that the content of cellulose II in that sample is very low or nonexistent. For pine and eucalyptus, the main peak reaches a final position after $3 \mathrm{~h}$, as shown in Figure 5a. For switchgrass, the main peak reaches a final position within $1 \mathrm{~h}$. These rates are much faster than those observed at $120^{\circ} \mathrm{C}$. The FWHM of the main peak for all samples is shown in Figure 5 b. In all samples, the FWHM increases rapidly to a maximum at $1 \mathrm{~h}$, consistent with the partial dissolution of cellulose I crystallites. Beyond $1 \mathrm{~h}$, the FWHM is roughly constant. After $12 \mathrm{~h}$ of pretreatment, the FWHM values are in the following order from greatest to least: eucalyptus, pine, switchgrass, and Avicel. This suggests that Avicel samples consist of larger crystalline domains, more highly ordered domains, or both. Whereas the transformation progressed much further at $160{ }^{\circ} \mathrm{C}$, it is not possible to quantify the evolution of cellulose II structure in the biomass samples with pretreatment time. This is due to possible overlap of the primary peak from cellulose I with the primary peak (doublet) for cellulose II. 

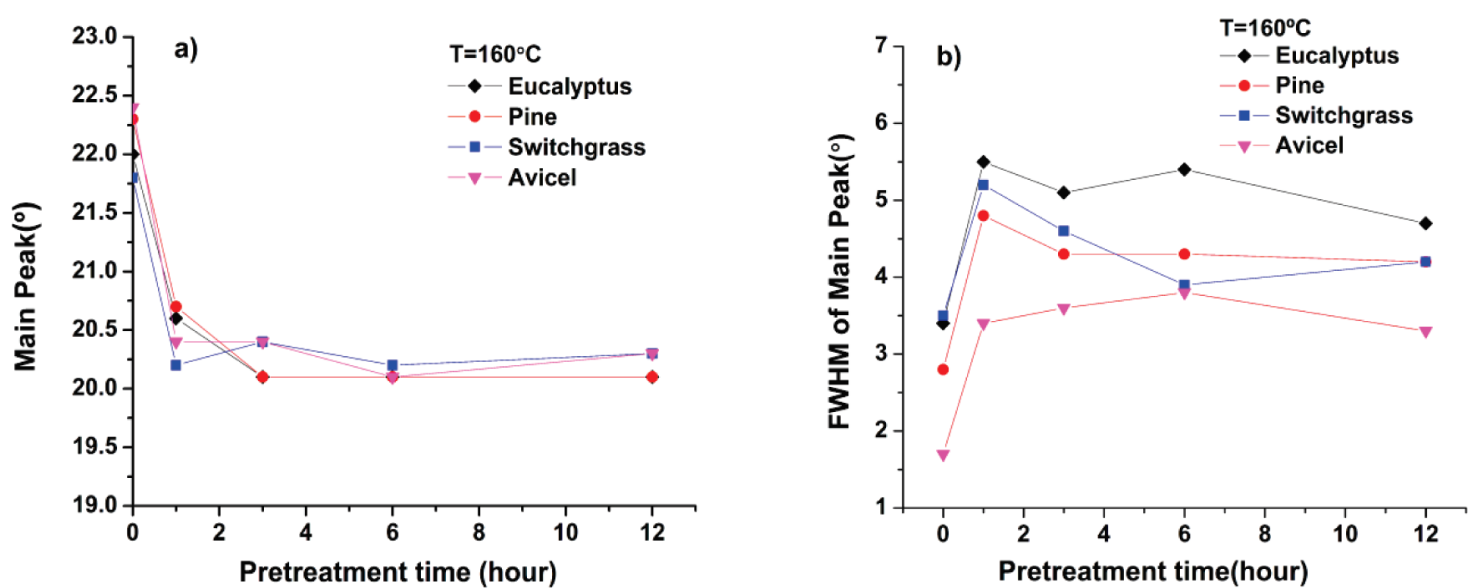

Figure 5. (a) Main peak of the XRD patterns of Avicel and biomass sample pretreated in [C2mim] OAc at $160^{\circ} \mathrm{C}$ for $1,3,6$, and $12 \mathrm{~h}$. (b) FWHM of main peak of the XRD patterns of Avicel and biomass sample pretreated in [C2mim] [OAc] at $160{ }^{\circ} \mathrm{C}$ for $1,3,6$, and $12 \mathrm{~h}$.

Whereas the peak at $12.1^{\circ}$ is a clear indication of cellulose II, it is weak and very broad in the biomass samples and is therefore not suitable for quantifying cellulose II content. Rather than quantifying the amount of cellulose II present in the biomass samples, we simply identify when cellulose II is present by the appearance of a peak at $12.1^{\circ}$. This is given in Table S1 of the Supporting Information, where we include the peak position and FWHM of all cases. Cellulose II is present in eucalyptus and switchgrass after processing for 1 to $3 \mathrm{~h}$ at $160{ }^{\circ} \mathrm{C}$. Also, the background at low angle is anomalously high in the switchgrass sample processed for $12 \mathrm{~h}$ which makes the peak at $\sim 12.1^{\circ}$ hardly discernible.

We note that an additional peak at $7^{\circ}$, corresponding to a $d$ spacing of 12.7 and $12.5 \AA$, is seen in the diffraction patterns of pretreated switchgrass and pine, respectively. This peak is present in the switchgrass samples pretreated for 3 and $6 \mathrm{~h}$ and in the pine samples pretreated for 3,6 , and $12 \mathrm{~h}$. The $d$ spacing remains constant with pretreatment time. The origin of this peak at low angle is unclear and warrants further study.

Influence of Crystal Structure on Enzymatic Saccharification. Cellulose II is thermodynamically more stable than cellulose I, however recent studies show that cellulose II is more readily digested than cellulose $I^{23,40}$ It has been argued that the van der Waals interaction between hydrogen-bonded sheets in cellulose I is stronger than that in cellulose II and this acts as a main factor to resist the hydrolysis by cellulase. ${ }^{40}$

The four IL pretreated feedstocks were hydrolyzed into reducing sugars (mainly glucose) using commercial cellulase enzymes. Their initial hydrolysis rates are compared for two pretreatment conditions $\left(120^{\circ} \mathrm{C}, 3 \mathrm{~h}\right.$ and $\left.160^{\circ} \mathrm{C}, 3 \mathrm{~h}\right)$ in Table $\mathrm{S} 2$ of the Supporting Information. Taking into account the hydrolysis reaction stoichiometry, $1 \mathrm{~g}$ of cellulose upon complete hydrolysis produces $1.11 \mathrm{~g}$ of glucose. ${ }^{13}$ Results show that after pretreatment for $3 \mathrm{~h}$ at $120^{\circ} \mathrm{C}$ Avicel has higher saccharification rate $(1765 \mathrm{mg} / \mathrm{L} / \mathrm{h})$ than Avicel pretreated for $3 \mathrm{~h}$ at $160{ }^{\circ} \mathrm{C}$. In addition, total cellulose digested after $24 \mathrm{~h}$ was also greater for $3 \mathrm{~h}$ of pretreatment at $120{ }^{\circ} \mathrm{C}$ compared with pretreatment at $160{ }^{\circ} \mathrm{C}$. These results are likely due to the differences in the cellulose II CrI. Shown in Figure 4, the CrI of cellulose II of the regenerated Avicel pretreated for $3 \mathrm{~h}$ at $160^{\circ} \mathrm{C}$ is higher than that for treatment at $120^{\circ} \mathrm{C}$.

In contrast with Avicel, all three biomass samples show a very large increase in saccharification efficiency at $160{ }^{\circ} \mathrm{C}$ compared with that at $120{ }^{\circ} \mathrm{C}$, exhibiting qualitatively different behavior than the pure cellulose substrate. For the three biomass feedstocks pretreated at 120 and at $160{ }^{\circ} \mathrm{C}$, switchgrass exhibited the highest cellulose-to-glucose yield and fastest hydrolysis rate, whereas pine exhibited the worst performance.

Surface Roughness As Determined by SANS. SANS was used to investigate the effect of IL pretreatment on the surface morphology of biomass samples. SANS and SAXS measure structure on length scales typically ranging from 10 to $1000 \AA$. SANS has the advantage of being nondestructive and more penetrating to most solid materials than SAXS, which allows better characterization of the internal structure of dense porous materials. SANS and SAXS are well-suited for characterizing the fractal dimensions of systems that exhibit self-similarity. Surface roughness is often modeled by a fractal dimension. ${ }^{41}$

The SANS data of untreated and pretreated $\left(120^{\circ} \mathrm{C}\right)$ switchgrass, pine, and eucalyptus samples are shown in Figure $6 a-c$, respectively. In the dry state, all SANS curves follow a power law function in the range of 0.1 to $0.004 \AA^{-1}$ despite the complex structure of the plant cell walls. The dependence is stronger at low $q<0.004 \AA^{-1}$, suggesting that structures with larger sizes are present. The scattering is dominated by the contrast (the difference in scattering length density (SLD)) between air and the biopolymer matrix; that is, the scattering arises mainly from surfaces or interfaces in the biomass. Air may exist in pores or cracks whose sizes vary from nanometers to micrometers in the cell wall. ${ }^{39,42,43}$ The roughness can be characterized by a surface fractal dimension, $D_{\text {surface }}=6-x$, where $x$ is the power law exponent obtained from the scattering data. ${ }^{42}$ For a perfectly smooth surface, $D_{\text {surface }}=2$ and increases beyond that value with increasing surface roughness. For untreated switchgrass, the exponent of the fitted power law function is 3.6 giving $D=2.4$, which corresponds to scattering from a rough surface $\left(0.004<q<0.1 \AA^{-1}\right)$. After IL pretreatment for 3 $\mathrm{h}$, the surface fractal dimension increased to 2.5 , indicating roughening of the internal surfaces as a result of the pretreatment. It continues to be 2.5 for $6 \mathrm{~h}$ until after $12 \mathrm{~h}$, where it dropped to 2.4. This indicates that smoother internal surfaces are formed. In contrast with switchgrass, both the eucalyptus and pine samples have smooth surfaces on this length scale with a fractal dimension of 2 . Upon pretreatment in IL at $120^{\circ} \mathrm{C}$ for 12 $\mathrm{h}$, the $D_{\text {surface }}$ of both eucalyptus and pine increased to 2.2 . 

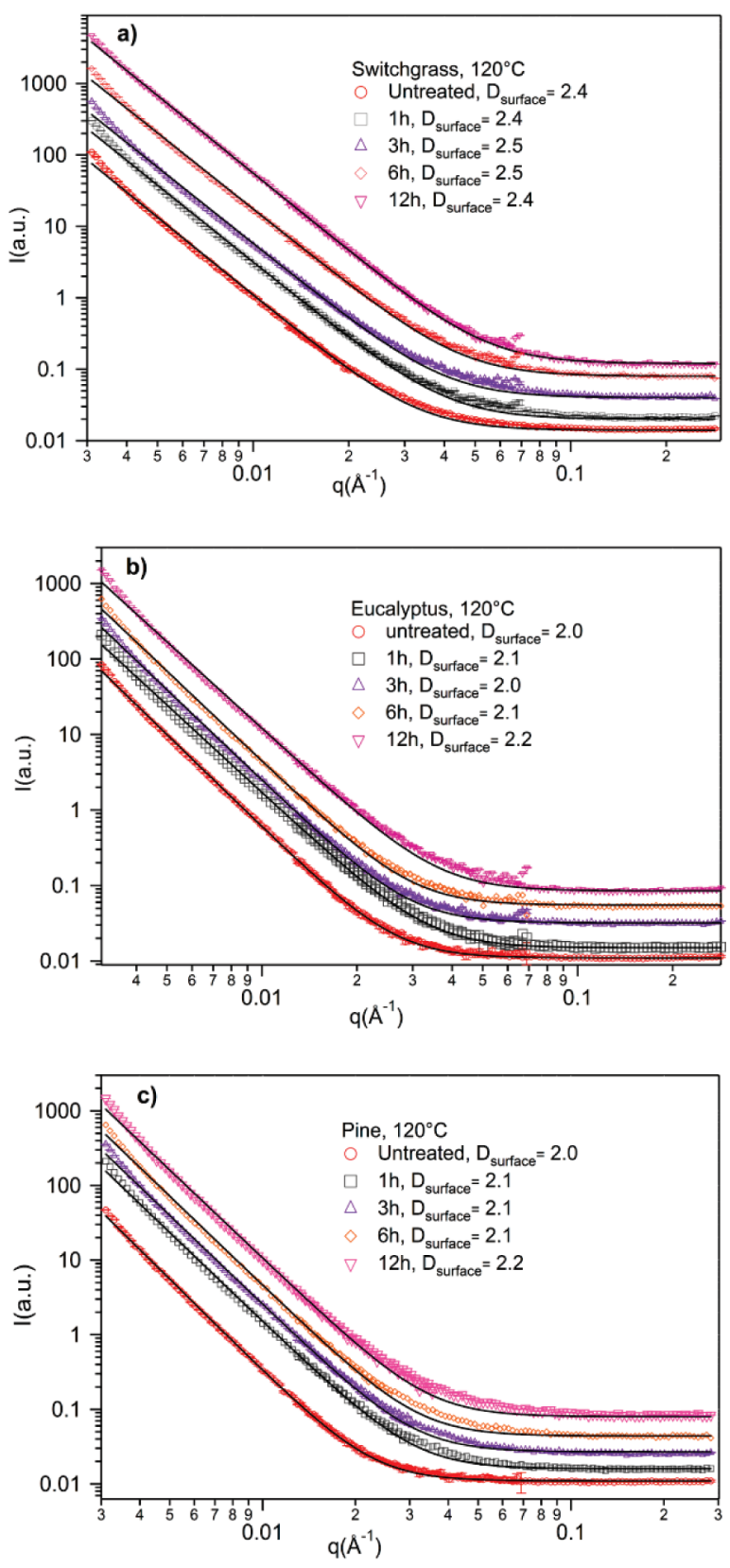

Figure 6. SANS data of (a) switchgrass, (b) eucalyptus, and (c) pine samples pretreated in $[\mathrm{C} 2 \mathrm{mim}][\mathrm{OAc}]$ at $120^{\circ} \mathrm{C}$ for $1,3,6$, and $12 \mathrm{~h}$. The solid line is a fit to a power law function, $I(q)=A q^{\alpha}+B$.

\section{DISCUSSION}

A prior autofluorescence study of the dissolution of switchgrass stems in $[\mathrm{C} 2 \mathrm{mim}][\mathrm{OAc}]$ provided direct imaging on the length scale of tens of micrometers of swelling of the cell walls, followed by dissolution of biomass. ${ }^{44}$ In this work, changes in the structure of the crystalline domains on the length scale of angstroms were followed by $\mathrm{XRD}$, and the impact of the pretreatment on the surface morphology on the order of 10 to 1000 A was measured by SANS. The application of these imaging and scattering techniques reveals complementary information necessary to more fully understand the process of IL pretreatment. Understanding changes in the crystalline structure and amorphous content as a function of pretreatment is important because they impact the efficiency of enzymatic hydrolysis.
Pretreating Avicel and biomass with ILs involves dissolution (or partial dissolution) and regeneration processes where the native crystalline structure is disrupted and restructures upon precipitation in water. ${ }^{7,13,14}$ XRD of an Avicel slurry precipitate before freeze-drying indicates the existence of cellulose II lattices (Figure S1 of the Supporting Information), consistent with previous observations that dissolved cellulose chains solvated in ILs crystallize into cellulose II in the presence of water. ${ }^{45} \mathrm{We}$ therefore conclude that the observed morphology is an effect induced by the precipitation of the biomass in water and that freeze-drying has little impact.

For the three biomass samples pretreated at $120{ }^{\circ} \mathrm{C}$, we observed a single main peak that shifted gradually with pretreatment time, in contrast with the results for Avicel, where the main peak for cellulose I disappeared and was replaced by the cellulose II doublet at the earliest pretreatment times. For the biomass samples, the gradual shift of the main peak position of cellulose I to a lower angle along with the absence of a peak at $12.1^{\circ}$ appears to indicate an expansion of the cellulose I lattice. Only after $12 \mathrm{~h}$ of pretreatment at $120^{\circ} \mathrm{C}$ was there evidence of cellulose II in the regenerated switchgrass in the form of a peak around $12.1^{\circ}$. Cellulose II was not evident in eucalyptus after $12 \mathrm{~h}$ of pretreatment at $120^{\circ} \mathrm{C}$ but was only evident for pretreatment at $160^{\circ} \mathrm{C}$. The difference observed between Avicel and the biomass samples may be due to the presence of lignin in the biomass samples interfering with cellulose I dissolution and structuring.

Whereas this is the first report suggesting lattice expansion of cellulose I in biomass samples upon pretreatment with an $\mathrm{IL}$, lattice expansion upon heating has been reported in prior XRD studies of cellulose $\mathrm{I}_{\alpha}$ and $\mathrm{I}_{\beta}$. In a study of cellulose $\mathrm{I}_{\beta}$ extracted from tunicate, a $1.9 \%$ increase in the intersheet distance was observed when heating from room temperature to $200{ }^{\circ} \mathrm{C}$, which was reversible upon cooling, indicating retention of cellulose $\mathrm{I}^{46}$ In another study of cellulose $\mathrm{I}_{\alpha}$ from Cladophora, the intersheet distance increased $6 \%$ upon heating to $280^{\circ} \mathrm{C}$, whereas the peak at $34.5^{\circ}$ showed little change. $^{26}$ This demonstrated that alignment of the cellulose chains in the microfibrils remained intact and that the cellulose I structure was retained, although with transformation from $\mathrm{I}_{\alpha}$ to $\mathrm{I}_{\beta} \cdot{ }^{26}$ In the present case, the shifts of the main peak correspond to $4.3,4.4$, and 4.7\% expansion in the direction perpendicular to the hydrogenbonded sheets for switchgrass, pine, and eucalyptus, respectively, after pretreatment at $120^{\circ} \mathrm{C}$ for $3 \mathrm{~h}$.

The diffraction patterns of cellulose in the biomass samples treated at 120 and $160{ }^{\circ} \mathrm{C}$ provide insight into the pathway by which the crystal structure transition occurs. For the biomass samples treated in IL at $120{ }^{\circ} \mathrm{C}$, the cellulose I lattice is mostly preserved for treatment up to $6 \mathrm{~h}$, evidenced by the persistence of the original three peaks in the spectrum. This implies that the original cellulose I microfibrils persist to some extent up to that point. The decrease in the height of the main peak as well as the broadening of the peak width suggests increased disorder in the parallel stacking of the sheets about the average intersheet distance, decrease in cellulose I crystallite size, or both. The shift of the main peak to lower angles indicates an increase in the distance between hydrogen-bonded sheets. For switchgrass, the alignment of the chains into microfibrils was eliminated after pretreatment at $120^{\circ} \mathrm{C}$ for $6 \mathrm{~h}$, as shown by the disappearance of the peak at $34.5^{\circ} .^{47}$ From that point on, the regenerated cellulose in the switchgrass sample starts to possess increasing cellulose II content. Progression through the latter two stages required more intense pretreatment for eucalyptus and even further intense pretreatment for pine. 
Variation of the surface roughness of recovered biomass samples after pretreatment is likely to be affected by the structure and morphology of biomass in [C2mim] $[\mathrm{OAc}]$ before precipitation as well as by the precipitation conditions. For constant precipitation conditions, an increase in the surface roughness, as observed for all three biomass samples, could result from partial delignification, partial dissolution of cellulose I microfibrils, or both. However, the fact that the decrease in surface roughness of the switchgrass samples pretreated for $12 \mathrm{~h}$ at $120^{\circ} \mathrm{C}$ coincides with the onset of cellulose II structure suggests that the cellulose crystalline structure is a major factor affecting the roughness in the size range measured by SANS. Therefore, we propose that partial disruption of cellulose I and delignification of biomass samples results in increased surface roughness, whereas the formation of cellulose II after regeneration results in smoother surfaces.

Another correlation in the data is that untreated pine and eucalyptus samples have very low surface roughness compared with that of untreated switchgrass, and these two biomass samples also showed slower cellulose I lattice expansion and dissolution upon pretreatment at $120^{\circ} \mathrm{C}$ than switchgrass. It may be that the smoothness is a result of a more extensive lignin composition mixed with the cellulose microfibrils in pine and eucalyptus, which could contribute to the slower transformation to cellulose II and the substantially lower hydrolysis rates after pretreatment at $120^{\circ} \mathrm{C}$.

The increased hydrolysis rate of Avicel upon transformation to cellulose II observed in this study is consistent with prior studies. $^{23,40}$ However, we observed that Avicel pretreated at $160{ }^{\circ} \mathrm{C}$ exhibits slower hydrolysis than for pretreatment at $120{ }^{\circ} \mathrm{C}$. We suggest that this is due to the lower cellulose II $\mathrm{CrI}$ for the sample processed at $120^{\circ} \mathrm{C}$. This trend for Avicel is strikingly different than the results for the biomass samples, where greatly increased hydrolysis rates at $160^{\circ} \mathrm{C}$ were observed in all cases relative to the rates at $120^{\circ} \mathrm{C}$. This suggests, as has been demonstrated by others, the presence of lignin-carbohydrate complexes that contribute to biomass recalcitrance and are degraded more efficiently at the higher temperature. The trend in hydrolysis rate for the biomass samples correlates with the conversion rates from cellulose I to cellulose II, as pine showed slower crystalline structure transformation than switchgrass, with eucalyptus falling in between. However, we emphasize that cellulose crystal structure content and morphology is only one of the potential factors that could contribute to the biomass recalcitrance. Variability in lignin-carbohydrate complexes among the three biomass samples could also explain the differences in hydrolysis characteristics.

\section{CONCLUSIONS}

Pretreatment of a pure cellulose substrate (Avicel) and three biomass samples with $[\mathrm{C} 2 \mathrm{mim}][\mathrm{OAc}]$ at 120 and $160{ }^{\circ} \mathrm{C}$ resulted in a loss of native cellulose crystalline I structure. However, the transformation processes were distinctly different for Avicel and for the biomass samples. For Avicel, a transformation to cellulose II occurred for all processing conditions. For the biomass samples, the data suggest that pretreatment for most conditions resulted in an expanded cellulose I lattice. For switchgrass, first evidence of cellulose II only occurred after $12 \mathrm{~h}$ of pretreatment at $120^{\circ} \mathrm{C}$. For eucalyptus, first evidence of cellulose II required more intense pretreatment $\left(3 \mathrm{~h}\right.$ at $\left.160^{\circ} \mathrm{C}\right)$. For pine, no clear evidence of cellulose II content was detected for the most intense pretreatment conditions of this study $(12 \mathrm{~h}$ at $\left.160{ }^{\circ} \mathrm{C}\right)$. The structural characterization was compared with measurements of enzymatic hydrolysis. Somewhat surprisingly, pretreatment of Avicel at $160{ }^{\circ} \mathrm{C}$ for $3 \mathrm{~h}$ led to a reduced hydrolysis rate relative to that for pretreatment at $120^{\circ} \mathrm{C}$, most likely because of a greater cellulose II CrI after treatment at $160{ }^{\circ} \mathrm{C}$. In contrast, pretreatment of the biomass samples at $160{ }^{\circ} \mathrm{C}$ greatly facilitated enzymatic hydrolysis relative to that for pretreatment at $120^{\circ} \mathrm{C}$. Combined with the results for Avicel, this demonstrates the primary importance of another factor, likely lignin-carbohydrate complexes, to hydrolysis rates for the biomass samples. Finally, among the biomass samples, switchgrass possessed much rougher internal surfaces, showed more rapid cellulose I lattice expansion and conversion to cellulose II, and showed substantially more rapid hydrolysis after pretreatment at $120{ }^{\circ} \mathrm{C}$ than pine. Results for eucalyptus fell in between but were closer to those for switchgrass. These observations could be explained by less extensive lignin intermixed with the cellulose microfibrils for switchgrass than for pine, although at the present, we have no direct evidence of that.

\section{ASSOCIATED CONTENT}

S Supporting Information. Synchrotron XRD of an Avicel slurry precipitate before freeze-drying; summary table of cellulose II secondary peak position and width in IL pretreated Avicel and lignocellulosic biomass; and summary table of enzymatic saccharification of IL pretreated Avicel and lignocellulosic biomass. This material is available free of charge via the Internet at http://pubs.acs.org.

\section{AUTHOR INFORMATION}

\section{Corresponding Author}

*E-mail: seesing@sandia.gov.

\section{ACKNOWLEDGMENT}

We thank Drs. Cheng Wang, Alexander Hexemer, and Mr. Alejandro Cruz Gonzalez for helping with tests at the Advanced Light Source of LBL. We thank Dr. Paul Adams (LBL) for reviewing the manuscript, Professor Sunkyu Park (North Carolina State University) for helpful discussions, and Mr. Miles Clift (Sandia National Laboratories) for assisting with XRD measurements. This work was part of the DOE Joint BioEnergy Institute (http://www.jbei.org) supported by the U.S. Department of Energy, Office of Science, Office of Biological and Environmental Research, through contract DE-AC0205CH11231 between Lawrence Berkeley National Laboratory and the U.S. Department of Energy. This research at Oak Ridge National Laboratory's High Flux Isotope Reactor was sponsored by the Scientific User Facilities Division, Office of Basic Energy Sciences, U.S. Department of Energy. G.C. acknowledges the EPSCoR Neutron Travel Fellowship through University of Tennessee.

\section{REFERENCES}

(1) Blanch, H. W.; Adams, P. D.; Andrews-Cramer, K. M.; Frommer, W. B.; Simmons, B. A.; Keasling, J. D. ACS Chem. Biol. 2008, 3, 17-20.

(2) Richard, T. L. Science 2010, 329, 793-796.

(3) Mosier, N.; Wyman, C.; Dale, B.; Elander, R.; Lee, Y. Y.; Holtzapple, M.; Ladisch, M. Bioresour. Technol. 2005, 96, 673-686. 
(4) Kumar, P.; Barrett, D. M.; Delwiche, M. J.; Stroeve, P. Ind. Eng. Chem. Res. 2009, 48, 3713-3729.

(5) Hendriks, A. T. W. M.; Zeeman, G. Bioresour. Technol. 2009, 100, 10-18.

(6) Dadi, A. P.; Schall, C. A.; Varanasi, S. Appl. Biochem. Biotechnol. 2007, 136-140, 407-421.

(7) Sun, N.; Rahman, M.; Qin, Y.; Maxim, M. L.; Rodríguez, H.; Rogers, R. Green Chem. 2009, 11, 646-655.

(8) Li, C.; Knierim, B.; Manisseri, C.; Arora, R.; Scheller, H. V.; Auer, M.; Vofgel, K. P.; Simmons, B. A.; Singh, S. Bioresour. Technol. 2010, 101, 4900-4906.

(9) Samayam, I. P.; Schall, C. A. Bioresour. Technol. 2010, $101,3561-3566$.

(10) Zhang, Y.-H. P.; Lynd, L. R. Biotechnol. Bioeng. 2004, $88,797-824$.

(11) Laureano-Perez, L.; Teymouri, F.; Alizadeh, H.; Dale, B. E. Appl. Biochem. Biotechnol. 2005, 121-124, 1081-1099.

(12) Hall, M.; Bansal, P.; Lee, J. H.; Realff, M. J.; Bommarius, A. S. FEBS Journal 2010, 277, 1571-1582.

(13) Dadi, A. P.; Varanasi, S.; Schall, C. A. Biotechnol. Bioeng. 2006, 95, 904-910.

(14) Kim, S.-J.; Dwiatmoko, A. A.; Choi, J. W.; Suh, Y.-.W.; Suh, D. J.; Oh, M. Bioresour. Technol. 2010, 101, 8273-8279.

(15) Sluiter, A.; Hames, B.; Ruiz, R.; Scarlata, C.; Sluiter, J.; Templeton, D. LAP-002 NREL Analytical Procedure; National Renewable Energy Laboratory: Golden, CO, 2004.

(16) Sluiter, A.; Hames, B.; Ruiz, R.; Scarlata, C.; Sluiter, J.; Templeton, D. LAP-005 NREL Analytical Procedure; National Renewable Energy Laboratory: Golden, CO, 2004.

(17) Obro, J.; Harholt, J.; Scheller, H. V.; Orfila, C. Phytochemistry 2004, 65, 1429-1438.

(18) Thygesen, A.; Oddershede, J.; Lilholt, H.; Thomsen, A. B.; Ståhl, K. Cellulose 2005, 12, 563-576.

(19) Park, S.; Baker, J. O.; Himmel, M. E.; Parilla, P. A.; Johnson, D. K. Biotechnol. Biofuels 2010, 3, 10.

(20) O'sullivan, A. C. Cellulose 1997, 4, 173-207.

(21) Sugiyama, J.; Vuong, R.; Chanzy, H. Macromolecules 1991, 24, 4168-4175.

(22) (a) Nishiyama, Y.; Sugiyama, J.; Chanzy, H.; Langan, P. J. Am. Chem. Soc. 2003, 125, 14300-14306. (b) Nishiyama, Y.; Langan, P; Chanzy, H. J. Am. Chem. Soc. 2002, 124, 9074-9082.

(23) Kumar, S.; Gupta, R.; Lee, Y. Y.; Gupta, R. B. Bioresour. Technol. 2010, 101, 1337-1347.

(24) Ago, M.; Endo, T.; Hirotsu, T. Cellulose 2004, 11, 163-167.

(25) Langan, P.; Nishiyama, Y.; Chanzy, H. J. Am. Chem. Soc. 1999, 121, 9940-9946.

(26) Wada, M.; Kondo, T.; Okano, T. Polym. J. 2003, 35, 155-159.

(27) Abe, K.; Yamamoto, H. J. Wood Sci. 2005, 51, 334-338.

(28) Newman, R. H. Cellulose 2008, 15, 769-778.

(29) Garvey, C. J.; Parker, I. H.; Simon, G. P. Macromol. Chem. Phys. 2005, 206, 1568-1575.

(30) Hori, R.; Wada, M. Cellulose 2006, 13, 281-290.

(31) Oh, S. Y.; Yoo, D. I.; Shin, Y; Kim, H. C.; Kim, H.,Y.; Chung, Y. S.; Park, W. H.; Youk, J. H. Carbohydr. Res. 2005, 340, 2376-2391.

(32) Široký, J.; Blackburn, R. S.; Bechtold, T.; Taylor, J.; White, P. Cellulose 2010, 17, 103-115.

(33) Agarwal, U. P.; Reiner, R. S.; Ralph, S. A. Cellulose 2010, 17, 721-733.

(34) Andersson, S.; Wikberg, H.; Pesonen, E.; Maunu, S. L.; Serimaa,

R. Trees 2004, 18, 346-353.

(35) Reddy, N.; Yang, Y. Biotechnol. Bioeng. 2007, 97, 1021-1027.

(36) Harris, D.; DeBolt, S. PLoS One 2008, 3, e2897-1-e2897-10.

(37) Popescu, C.-M.; Popescu, M.- C.; Singurel, G.; Vasile, C.; Argyropoulos, D. S.; Willfor, S. Appl. Spectrosc. 2007, 61, 1168-1177.

(38) Zhao, H.; Jones, C. L.; Baker, G. A.; Xia, S.; Olubajo, O.; Person,

V. N. J. Biotechnol. 2009, 139, 47-54.

(39) Fahlén, J.; Salmén, L. Biomacromolecules 2005, 6, 433-438.

(40) Wada, M.; Ike, M.; Tokuyasu, K. Polym. Degrad. Stab. 2010, 95, 543-548.
(41) Bale, H. D.; Schmidt, P. W. Phys. Rev. Lett. 1984, 53, 596-599.

(42) Kent, M. S.; Cheng, G.; Murton, J. K.; Carles, E. L.; Dibble, D. C.; Zendejas, F.; Rodriquez, M. A.; Tran, H.; Holmes, B.; Simmons, B. A.; Knierim, B.; Auer, M.; Banuelos, J. L.; Urquidi, J.; Hjelm, R. P. Biomacromolecules 2010, 11, 357-368.

(43) Wan, J.; Wang, Y.; Xiao, Q. Bioresour. Technol. 2010, 101, 4577-4583.

(44) Singh, S.; Simmons, B. A.; Vogel, K. P. Biotechnol. Bioeng. 2009, $104,68-75$.

(45) Fengel, D.; Stoll, M. Wood Sci. Technol. 1989, 23, 85-94.

(46) Wada, M. J. Polym. Sci., Part B: Polym. Phys. 2002, 40, 1095-1102.

(47) Dinand, E.; Vignon, M.; Chanzy, H.; Heux, L. Cellulose 2002, 9, 7-18. 